\title{
The associations between weight-related anthropometrics during childhood and lung function in late childhood: a retrospective cohort study
}

Kristine Kjer Byberg ${ }^{1 *}$ D, Ingvild Bruun Mikalsen ${ }^{1,2}$, Geir Egil Eide ${ }^{3,4}$, Michele R. Forman ${ }^{5}$, Pétur Benedikt Júlíusson ${ }^{2,6}$ and Knut Øymar ${ }^{1,2}$

\begin{abstract}
Background: An association between body weight in childhood and subsequent lung function and asthma has been suggested, but few longitudinal studies exist. Our aim was to explore whether weight-related anthropometric measurements through childhood were associated with lung function in late childhood.

Methods: From an original nested case-control study, a cohort study was conducted, where lung function was measured in 463 children aged 12.8 years, and anthropometry was measured at several ages from birth through 12.8 years of age. Associations between anthropometrics and lung function were analysed using multiple linear and fractional polynomial regression analysis.

Results: Birthweight and body mass index $\left(\mathrm{BMl} ; \mathrm{kg} / \mathrm{m}^{2}\right)$ at different ages through childhood were positively associated with forced vital capacity in percent of predicted (FVC \%) and forced expiratory volume in the first second in percent of predicted $\left(\mathrm{FEV}_{1} \%\right)$ at 12.8 years of age. BMI, waist circumference, waist-to-height ratio and skinfolds at 12.8 years of age and the change in BMI from early to late childhood were positively associated with FVC \% and $\mathrm{FEV}_{1} \%$ and negatively associated with $\mathrm{FEV}_{1} / \mathrm{FVC}$ and forced expiratory flow at $25-75 \%$ of FVC/FVC. Interaction analyses showed that positive associations between anthropometrics other than BMI and lung function were mainly found in girls. Inverse U-shaped associations were found between BMl at the ages of 10.8/11.8 (girls/boys) and 12.8 years (both genders) and $\mathrm{FVC} \%$ and $\mathrm{FEV}_{1} \%$ at 12.8 years of age.

Conclusions: Weight-related anthropometrics through childhood may influence lung function in late childhood. These findings may be physiological or associated with air flow limitation. Inverse U-shaped associations suggest a differential impact on lung function in normal-weight and overweight children.
\end{abstract}

Trial registration: This study was observational without any health care intervention for the participants. Therefore, no trial registration number is available.

Keywords: Birth weight, Body mass index, Skin fold thickness, Lung function tests, Child

\footnotetext{
* Correspondence: kristine.kjer.byberg@sus.no

'Department of Paediatrics, Stavanger University Hospital, POB 8100, N-4068

Stavanger, Norway

Full list of author information is available at the end of the article
} 


\section{Background}

Birth weight is positively associated with subsequent lung function in both childhood and adulthood [1-3]. This agrees with Barker's results, suggesting that an adverse environment and poor growth in utero may lead to impaired growth of airways and subsequent reduced airway calibre [4].

In adulthood, body mass index (BMI) and different measures of body composition are inversely associated with lung function $[5,6]$; however, in childhood, these findings are less consistent. Cross-sectional studies of children and adolescents report positive associations between BMI or other anthropometric measures and forced vital capacity (FVC) and forced expiratory volume in the first second $\left(\mathrm{FEV}_{1}\right)$, but negative associations with $\mathrm{FEV}_{1} / \mathrm{FVC}$ [7-10]. The impact of catch-up growth and change in weight over time on lung function in later childhood has been studied in longitudinal studies, with inconsistent results reported at different ages [11-13]. Moreover, the age at which a possible transition occurs from the initial positive to the negative associations between anthropometrics and lung function is not known.

Studies including obese children have shown a reduction in static lung volume related to the degree of obesity [14] and inverse associations between waist circumference, skinfolds and lung function [8], but study results were inconsistent [15]. Overweight/obesity has been associated with childhood asthma; however, the causal pathway for this relationship remains unknown [16].

BMI is a surrogate measure of body fat and reflects total body mass; however, it does not provide information about fat distribution, and it may misclassify persons with welldeveloped musculature and children with low to normal BMI [17]. Body weight and BMI do not distinguish between fat mass and lean (muscle) mass, which may have opposite effects on lung function [18]. Therefore, other weightrelated anthropometrics like waist circumference and skinfolds have been suggested as markers of body fat distribution [19-21]. The impact of waist circumference and skinfolds on lung function during childhood has not been studied in detail.

The present cohort study was derived from a casecontrol study nested within a birth cohort. The aim was to study the associations between birthweight, BMI, changes in BMI, waist circumference, triceps- and subscapular skinfolds during childhood on lung function at 12.8 years of age. We hypothesized that childhood overweight or accelerated weight gain is associated with an obstructive lung function pattern in late childhood.

\section{Methods}

Study population and design (Fig. 1)

The study was a part of the 'Stavanger study' which is described in detail previously [22]. A flow-chart presenting number of participants and loss to follow-up is shown in Fig. 1. All children born at Stavanger University Hospital in 1993-1995 $(n=12,804)$ comprised a population-based birth cohort. From this cohort, a nested case-control study of preeclampsia exposure for perinatal risks was conducted, where offspring exposed to maternal preeclampsia and unexposed offspring were identified as follows: For each exposed offspring, two matched unexposed offspring

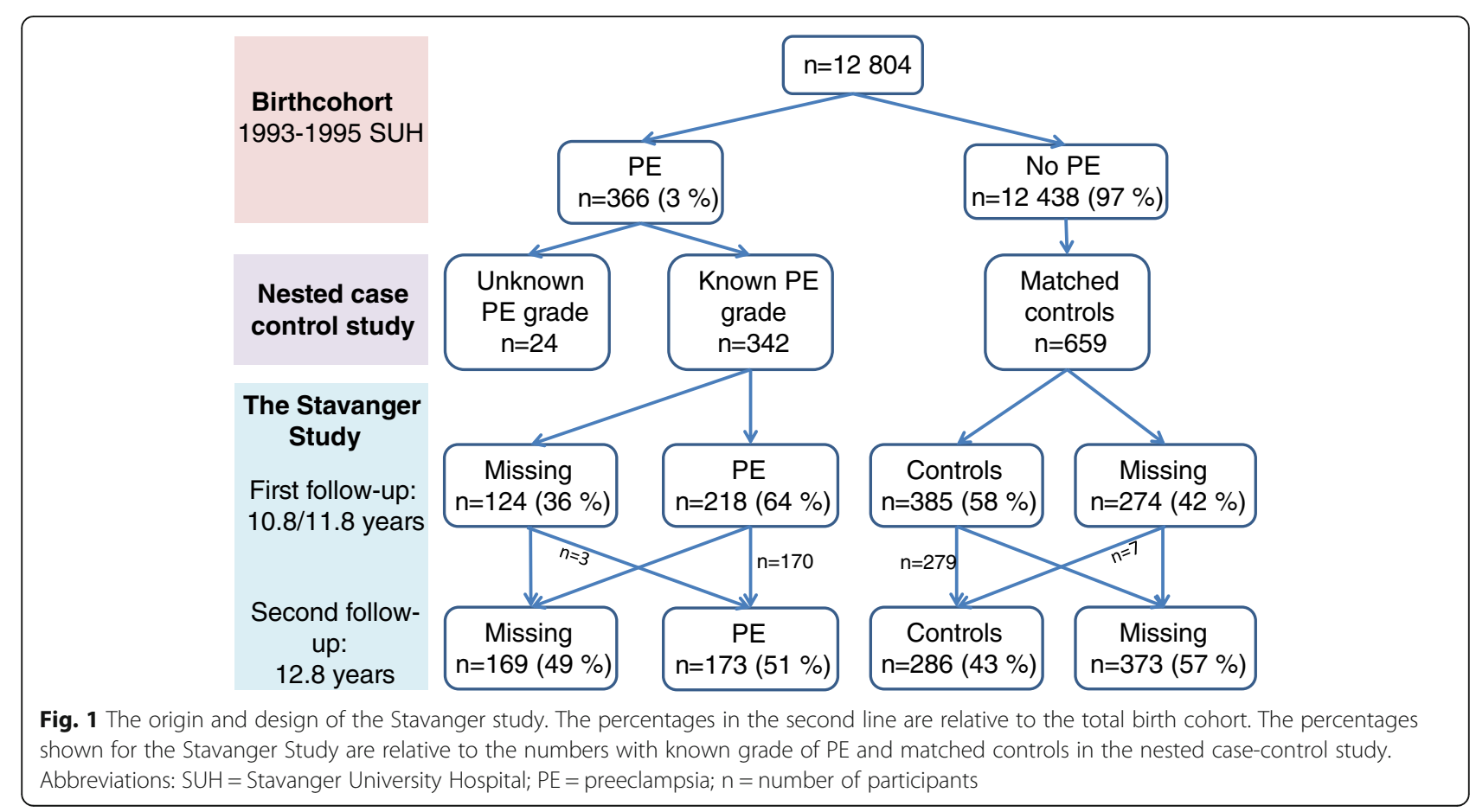


were selected: one was defined as the next born in the hospital (i.e. a birth date and gender match) and one as the next born matched on maternal age (i.e. a risk factor for preeclampsia). Children without adequate information about preeclampsia severity were excluded from analyses [23]. The 'Stavanger study' was conducted as a follow-up of the nested case-control study, where the children were invited to participate in two follow-ups in late childhood: a first follow-up at the target ages of 10.8 years (girls) and 11.8 years (boys), and a second follow-up at the target age of 12.8 years (both genders) [24]. The ages for the first and second follow-ups were selected to coincide with the age of pubertal onset of Norwegian children and the age of menarche of the girls respectively. In the current study, data from the follow-up of the nested case-control study were treated as those of a retrospective cohort study, and to avoid bias, all analyses were adjusted for preeclampsia. Owing to missing participants, the original matching of maternal age and birth date was ignored in the analyses; therefore, all analyses were adjusted for maternal age. All children with information about preeclampsia severity who participated in lung function testing at the second follow-up formed the analytic sample.

The study was approved by the Norwegian Data Inspectorate, the Regional Committee for Ethics in Medical Research for western Norway, and the Institutional Review Boards of the National Cancer Institute and University of Texas at Austin, United States. At follow-up, mothers and children signed an informed consent/assent form.

\section{Outcomes recorded at $\mathbf{1 2 . 8}$ years of age}

Lung function was measured by spirometry according to established guidelines [25] by using a Vmax Encore spirometer (Sensor Medics Inc., Anaheim, USA), and FVC, $\mathrm{FEV}_{1}$ and forced expiratory flow at $25-75 \%$ of $\mathrm{FVC}$ $\left(\mathrm{FEF}_{25-75 \%}\right)$ were recorded. Measurements were compared to values predicted by standard reference equations [26] and reported as percentages of predicted $\left(\mathrm{FVC} \%, \mathrm{FEV}_{1} \%\right.$, and $\mathrm{FEV}_{1} / \mathrm{FVC} \%$ ). The $\mathrm{FEF}_{25-75 \%} / \mathrm{FVC}$ ratio was given as a percentage as no predicted values were available.

\section{Predictors}

Birthweight was abstracted from hospital records. Recordings of length/height and weight measurements were collected from well-child clinics at the target ages of 3, 6 and 12 months and 4 years. Trained nurse researchers measured the height, weight, triceps skinfold and waist circumference twice in offspring at both follow-ups at the ages of 10.8/11.8 (girls/boys) and 12.8 years (both genders). The subscapular skinfold was measured twice at the second follow-up [22, 27]. At the follow-ups, but not at birth or at the well-child clinics, the average of two measurements was used in the analysis. The waist-to-height ratio was calculated as the waist circumference divided by height.

Change in weight and BMI standard deviation scores (SDS) was calculated as the difference in weight and BMI SDS from each target age to the next. Weight status was classified as an ordinal variable with 6 levels: thinness grades 1, 2 and 3, normal-weight, overweight and obese, by comparing BMI with age- and sex-specific cut-off values of the International Obesity Task Force (IOTF) [28]. Accelerated weight gain was defined as an increase in BMI SDS between two target ages.

At 12.8 years of age, the children answered a validated questionnaire from the International Study of Asthma and Allergy in Childhood (ISAAC) recording symptoms of asthma [29]. Current asthma was defined as a positive answer to 'asthma ever' and a positive answer to at least one of the two questions on wheezing/ whistling/chest tightness or the use of asthma medication during the last 12 months. Missing answers were interpreted as negative.

\section{Potential confounders}

Mothers completed a questionnaire at the first follow-up with information about birth order, breastfeeding, mother's doctor's diagnosis of asthma and mother's education. Information about gestational age was abstracted from hospital records. Potential confounders included the following categorical and continuous variables: gender, birth order (firstborn or later), gestational age (weeks), duration of breastfeeding (categories: none, $<3$ months, $>3$ months), mother's preeclampsia (none, mild/moderate, severe) [30], mother's BMI (weight at first antenatal visit and height at the first follow-up), mother's smoking (at first antenatal visit), mother's doctor-diagnosed asthma, mother's education ( $<9$ years, $9-12$ years, $>12$ years) and mother's age [24]. Lung function measurements were reported as percentages of predicted values standardized according to age, height, gender and ethnicity. Therefore, age and height were not included as potential confounders.

At the first follow-up at age 10.8/11.8 years (girls/boys), the 'Stanford Brief Activity Survey', a questionnaire validated for adults, was administered to the mothers for responses about the child's physical activity [31]. Specifically, the answers to the following questions were obtained: 'How active was your child at 3-6 years?' and 'How active was your child at $6-10$ years?' The response categories were categorized as passive and/or not so active $=$ low activity, active $=$ normal, very active $=$ high activity .

For the analyses of the association between changes in weight/BMI SDS and lung function, the weight/BMI SDS before each change was included as a possible confounder.

If child's asthma is causally related to anthropometrics and/or lung function, the direction of causality may go either way. Therefore, it was not included as a 
confounder. The confounders are illustrated in a $\mathrm{Di}$ rected Acyclic Graph (Additional file 1: Figure S1) [32].

\section{Statistics}

As the lung function measurements were added as outcomes in an established follow-up study, power calculations were not performed prior to study start.

For normally distributed variables, means with standard deviations for descriptive statistics and Gosset's unpaired t-test for group comparisons were calculated.

There was a wide range of gestational ages at birth owing to the inclusion of offspring of preeclampsia and normotensives and a wide age range at later well-child visits, and analysing actual values for anthropometrics as predictors would not be appropriate. Therefore, standard deviation scores (SDS) based on anthropometric values and actual ages were computed from relevant references [20, 21, 33, 34]. Conversions into SDS were performed using $\mathrm{R}$ version 2.6.2 (R Development Core Team, Vienna, Austria).

The associations between BMI SDS and outcomes of lung function at 12.8 years were analysed by multiple linear regression analyses. Separate analyses of the predictors were performed for each target age, for each change in weight/BMI SDS in early childhood and both follow-ups. Each variable was entered separately into simple regression models. Next, all potential confounders were included in fully adjusted models. Thereafter, we tested for interactions between predictors and gender. Owing to missing values, the number of participants varied between the different analyses.

For each predictor, estimated coefficients (b) with F-test $P$-values and 95\% confidence interval (CI) are reported. The significance level was chosen as 0.05 for all tests.

To study possible non-straight-line associations between BMI SDS and the outcomes, multiple fractional polynomial regression analysis (MFPR) was used with the requirement of $p \leq 0.05$ for non-straight-line terms. Finally, separate analyses were performed for each gender.

IBM SPSS for Windows (Version 22.0.0, Chicago, Ill., USA) was used for descriptive statistics and linear regression, and Stata SE 14 was used for MFPR.

\section{Results}

\section{Characteristics of the participants (Tables 1, 2 and 3)}

In total, 468 children consented to participate at the second follow-up at 12.8 years of age, but information about preeclampsia severity was available for only 459 children (173 exposed to preeclampsia and 286 unexposed). Successful lung function measurement was performed in 453 of these children, and they constituted the analytic sample. Of these, 446 children also completed the ISAAC questionnaire. The number of anthropometric measures from each target age differs owing to missing data from the well-child visits. The response rate for each potential confounder varies owing to missing data from the questionnaires and antenatal visits.

Baseline characteristics were similar between those who assented to the first follow-up only and those who assented to both follow-ups [24]. The mothers of the children who assented to the second follow-up were older than the mothers of the children who did not assent. Otherwise, perinatal characteristics were similar between those who assented or did not assent to both follow-ups [35]. The available clinical characteristics of the 463 children who performed lung function tests are shown in Table 1. The number of children in the different IOTF weight classes at 4 years of age and both follow-ups is shown in Table 2. Compared to children without asthma, children with current asthma had similar FVC \% and $\mathrm{FEV}_{1} \%$, lower $\mathrm{FEF}_{25-75 \%} / \mathrm{FVC}$ and a tendency for lower $\mathrm{FEV}_{1} / \mathrm{FVC} \%$ (Table 3 ).

\section{Anthropometrics and lung function (Tables 4 and 5 and Fig. 2)}

Birthweight and BMI SDS at all ages were positively associated with $\mathrm{FVC} \%$ and $\mathrm{FEV}_{1} \%$ at 12.8 years of age. BMI SDS at the ages of 10.8/11.8 (girls/boys) and 12.8 years (both genders) was negatively associated with $\mathrm{FEV}_{1} / \mathrm{FVC} \%$ and $\mathrm{FEF}_{25-75 \%} / \mathrm{FVC}$ at 12.8 years of age (Table 4).

Other anthropometrics were positively associated with $\mathrm{FVC} \%$ and $\mathrm{FEV}_{1} \%$, but interaction analyses showed that for most variables this was only found in girls. Several of these variables were negatively associated with $\mathrm{FEV}_{1}$ / $\mathrm{FVC} \%$ and $\mathrm{FEF}_{25-75 \%} / \mathrm{FVC}$, without differences between genders (Table 4).

Change in BMI SDS from 1 to 4 years was positively associated with $\mathrm{FVC} \%$ and $\mathrm{FEV}_{1} \%$. Change in BMI SDS from the age of 4 to $10.8 / 11.8$ years (girls/boys) was positively (significant or near significant) associated with $\mathrm{FVC} \%$ and $\mathrm{FEV}_{1} \%$ and negatively associated with $\mathrm{FEV}_{1} /$ $\mathrm{FVC} \%$ and $\mathrm{FEF}_{25-75 \%} / \mathrm{FVC}$ (Table 5).

In the MFPR analyses, significant inverse U-shaped associations were found between BMI SDS at the age of 10.8/11.8 (girls/boys) and FVC \% and $\mathrm{FEV}_{1} \%$, but after stratification for gender, these associations were found only for girls. Inverse U-shaped associations were also found between BMI SDS at the age of 12.8 years (both genders) and $\mathrm{FVC} \%$ and $\mathrm{FEV}_{1} \%$ and between subscapular skinfold at 12.8 years of age and $\mathrm{FEV}_{1} \%$ (Figure 2). The functions showed a linear increase until a deflection point approximately at BMI of 1 SDS. No other nonstraight-line associations were found between anthropometric measures and lung function.

\section{Discussion}

In this retrospective cohort study from birth to 12.8 years of age, after adjustment for confounders, weight-related 
Table 1 Clinical characteristics of 463 Norwegian children delivered at Stavanger University Hospital in Norway 1993-1995 according to anthropometrics predictors

\begin{tabular}{|c|c|c|c|c|c|}
\hline Predictor & $\mathrm{n}$ & Mean & SD & SDS mean & SD of SDS \\
\hline \multicolumn{6}{|l|}{ Anthropometrics } \\
\hline Birthweight (kg) & 452 & 3.36 & 0.73 & -0.20 & 1.22 \\
\hline BMI 3 months & 419 & 16.4 & 1.52 & 0.04 & 0.99 \\
\hline BMI 6 months & 434 & 17.2 & 1.56 & 0.12 & 1.06 \\
\hline BMI 1 year & 433 & 17.2 & 1.51 & 0.21 & 1.10 \\
\hline BMI 4 years & 386 & 15.9 & 1.38 & -0.08 & 1.06 \\
\hline BMI 10.8/11.8 years $^{\mathrm{a}}$ & 442 & 17.8 & 2.81 & -0.21 & 1.16 \\
\hline BMI 12.8 years & 453 & 18.8 & 2.96 & -0.10 & 1.17 \\
\hline \multicolumn{6}{|l|}{ WC } \\
\hline 10.8/11.8 years ${ }^{\mathrm{a}}$ & 442 & 63.0 & 7.49 & 0.07 & 1.08 \\
\hline 12.8 years & 453 & 68.2 & 7.75 & 0.45 & 1.01 \\
\hline \multicolumn{6}{|l|}{$\mathrm{WH} \mathrm{tR}$} \\
\hline $10.8 / 11.8$ years $^{a}$ & 442 & 0.42 & 0.04 & 0.05 & 1.11 \\
\hline 12.8 years & 453 & 0.43 & 0.05 & 0.45 & 0.99 \\
\hline \multicolumn{6}{|l|}{ TSF } \\
\hline 10.8/11.8 years $^{a}$ & 439 & 11.5 & 4.50 & -0.27 & 1.11 \\
\hline 12.8 years & 452 & 12.2 & 4.86 & -0.14 & 1.06 \\
\hline \multicolumn{6}{|l|}{ SSF } \\
\hline 12.8 years & 437 & 8.34 & 3.93 & -0.35 & 1.01 \\
\hline Change in weight/BMl & & $\begin{array}{l}\text { Change in weight } \\
(\mathrm{kg}) \text { or BMl }\end{array}$ & SD & Change in SDS & SD of SDS \\
\hline Birthweight-3 months (kg) & 430 & 2.71 & 0.71 & 0.11 & 1.26 \\
\hline BMI 3-6 months & 418 & 0.82 & 1.08 & 0.09 & 0.74 \\
\hline BMI 6-12 months & 431 & -0.02 & 1.09 & 0.09 & 0.77 \\
\hline BMI 1-4 years & 383 & -1.38 & 1.39 & -0.31 & 1.01 \\
\hline BMI 4-10.8/11.8 years ${ }^{a}$ & 381 & 1.90 & 2.48 & -0.14 & 1.10 \\
\hline BMI 10.8/11. $8^{\mathrm{a}}-12.8$ years & 442 & 1.07 & 1.52 & 0.11 & 0.67 \\
\hline
\end{tabular}

Abbreviations: SD standard deviation, SDS SD score, BMI, body mass index $\left(\mathrm{kg} / \mathrm{m}^{2}\right), W C$ waist circumference (cm), WHtR waist-to-height ratio, TSF triceps skinfold $(\mathrm{mm})$, SSF subscapular skinfold $(\mathrm{mm})$

${ }^{a} 10.8$ years for girls, 11.8 years for boys

Table 2 The distribution of extended IOTF BMI classes for the study cohort of children delivered at Stavanger University Hospital in Norway 1993-95 at 4, 10.8/11.8 and 12.8 years of age

\begin{tabular}{lccc}
\hline Extended IOTF BMI class & $\begin{array}{l}4 \text { years of age } \\
n=375\end{array}$ & $\begin{array}{l}10.8 / 11.8 \text { years } \\
\text { of age } \\
n=442\end{array}$ & $\begin{array}{l}12.8 \text { years } \\
\text { of age } \\
n=453 \\
\mathrm{n}(\%)\end{array}$ \\
\hline Thinness grade 3 & $1(0.3)$ & $3(0.7)$ & $6(1.3)$ \\
Thinness grade 2 & $6(1.6)$ & $11(2.5)$ & $9(2.0)$ \\
Thinness grade 1 & $31(8.3)$ & $52(11.8)$ & $47(10.4)$ \\
Normal weight & $297(79.2)$ & $315(71.3)$ & $330(72.8)$ \\
Overweight & $35(9.3)$ & $51(11.5)$ & $50(11.0)$ \\
Obese & $5(1.3)$ & $10(2.3)$ & $11(2.4)$ \\
\hline
\end{tabular}

Abbreviations: IOTF International Obesity Task Force, BMI body mass index ${ }^{\mathrm{a}} 10.8$ years for girls, 11.8 years for boys anthropometrics through childhood were positively associated with $\mathrm{FVC} \%$ and $\mathrm{FEV}_{1} \%$ at 12.8 years of age. Different weight related anthropometrics in late childhood and change in BMI from early to late childhood were negatively associated with $\mathrm{FEV}_{1} / \mathrm{FVC} \%$ and $\mathrm{FEF}_{25-75 \%} /$ FVC at 12.8 years of age. BMI SDS at the age of 10.8/ 11.8 years (girls/boys) and 12.8 years (both genders) had an inverse U-shaped association with FVC \% and $\mathrm{FEV}_{1} \%$, potentially indicating that an increase in BMI over a given threshold adversely influences lung function. For the anthropometric variables other than BMI, the positive associations with lung function were generally only found for girls.

The positive associations of anthropometric measures with $\mathrm{FVC}$ and $\mathrm{FEV}_{1}$ and the negative associations with $\mathrm{FEV}_{1} / \mathrm{FVC}$ and $\mathrm{FEF}_{25-75 \%} / \mathrm{FVC}$ at 12.8 years of age are consistent with the results from several cross sectional [7-10] 
Table 3 Comparisons of different lung function variables at 12.8 years for the study cohort of children without and with asthma who were delivered at Stavanger University Hospital in Norway in 1993-1995

\begin{tabular}{|c|c|c|c|c|}
\hline \multirow[t]{2}{*}{ Lung function measure } & $\begin{array}{l}\text { All } \\
n=453^{\mathrm{a}}\end{array}$ & $\begin{array}{l}\text { No asthma } \\
n=409\end{array}$ & $\begin{array}{l}\text { Current asthma } \\
n=37\end{array}$ & \multirow[t]{2}{*}{$\begin{array}{l}\text { T-test } \\
p \text {-value }\end{array}$} \\
\hline & Mean (SD) & Mean (SD) & Mean (SD) & \\
\hline FVC \% & $100.1(11.6)$ & $100.2(11.8)$ & $101.1(9.5)$ & 0.658 \\
\hline FEV1\% & $97.5(10.7)$ & $97.6(10.8)$ & $96.2(10.0)$ & 0.456 \\
\hline FEV1/FVC \% & $97.1(7.5)$ & $97.2(7.5)$ & $94.9(7.6)$ & 0.069 \\
\hline $\mathrm{FEF}_{25-75 \%} / \mathrm{FVC}$ & $93.0(23.5)$ & $93.7(23.7)$ & $83.5(20.8)$ & 0.012 \\
\hline
\end{tabular}

Abbreviations: SD standard deviation, FVC \% forced vital capacity in percent of predicted, FEV1\% forced expiratory volume in first second in percent of predicted, FEV1/FVC \% ratio of FEV1 over FVC in percent of predicted, $F_{25} 25-75 \% / F V C$ ratio of forced expiratory flow between $25 \%$ and $75 \%$ of the forced vital capacity over FVC given as a percentage value

anformation on asthma diagnosis was missing for 7 children

and longitudinal studies in children [3, 12, 13, 36]. Similar results were found in a recent meta-analysis of 25,000 children from 24 European birth cohorts [37], but the age of lung function and anthropometric measurements differs between studies [3, 7, 9, 10, 12, 36, 37].

We found positive overall straight-line associations for birthweight and accelerated weight gain at the ages from 1 to 4 years and from 4 to $10.8 / 11.8$ years (girls/boys) with lung function at 12.8 years of age. This is in accordance with another study reporting a positive association both between rapid weight gain from 3 to 7 years of age and FVC and $\mathrm{FEV}_{1}$ at 15 years of age [12]. The positive associations between changes in BMI with lung function, both at the ages of $1-4$ years and 4 to $10.8 / 11.8$ years (girls/ boys), were in contrast to the results from a recent published study of 1740 Australian children followed from birth to 21 years of age [38]. The authors found that catch-up growth during the first 5 years of life had a positive effect on lung function at 21 years of age, whereas an inverse effect on lung function was found in men if the weight gain or obesity started after 5 years of age [13]. Differences in results between studies may be due to different predictors and ages of anthropometric measurements.

The reasons for the associations between anthropometrics and lung function found by us and others are not clear. Within a normal BMI range, it may seem that accelerated weight gain through childhood is associated with both increased lung volumes (FVC) and airway size $\left(\mathrm{FEV}_{1}\right)$, but more so for lung volumes [7, 12, 37]. This disproportionate growth between lung size and airway calibre during childhood has been called 'dysanapsis', by many considered a physiological phenomenon and without clinical relevance for airflow limitation in individuals $[39,40]$. However, the lower $\mathrm{FEV}_{1} / \mathrm{FVC}$ ratio related to BMI and weight gain in childhood has by some authors been interpreted as a flow limitation [10, 36, 39]. Recently, in a publication including 6 cohorts of children, dysanapsis defined as a normal FVC and $\mathrm{FEV}_{1}$ and a low $\mathrm{FEV}_{1} / \mathrm{FVC}$ ratio was associated with disease severity in obese children with asthma [41].
Asthma may be related to lung function, but is a heterogeneous disease and in clinical practice not a diagnosis with highly specific criteria. Furthermore, the direction of possible causality between child's asthma and anthropometrics and/or lung function may go either way, and asthma was not included as a potential confounder. We found no considerable difference in lung function between those children who did and did not report asthma. In a previously published paper of the same cohort, we found no association between childhood anthropometrics and asthma at 12.8 years of age [27], consistent with an Italian cross-sectional study of 2393 children aged 10-17 years, the negative association between weight and $\mathrm{FEV}_{1} / \mathrm{FVC}$ was independent of wheeze or other respiratory symptoms [7]. In contrast, two large scale studies have shown positive associations between rapid weight gain during early childhood and asthma and wheeze in later childhood [12, 42]. Consistently, in a meta-analysis including 1.4 million participants aged 0-19 years, overweight and obesity were positively associated with childhood asthma [16].

The pattern of associations between early-life anthropometrics and lung function discussed above is in contrast to equivalent studies in adults, showing negative associations between different anthropometrics and both FVC and $\mathrm{FEV}_{1}[5,6]$. A study including longitudinal data concluded that an initial positive association between BMI in childhood and adult FVC and $\mathrm{FEV}_{1}$ was likely to be attributable to greater childhood lean body mass and not greater fat mass alone [5]. BMI in normalweight children is more a surrogate marker of lean body mass than fat mass, suggesting that muscle mass increases in parallel with BMI; this could explain the different results in children and adults [18]. Skinfolds and waist circumference may be better markers of adiposity than BMI in children [19-21]. However, we found equivalent associations of BMI, waist circumference and skinfolds with lung function variables, which may suggest that BMI also reflects body fat in these children, and it may contradict the interpretation that the 


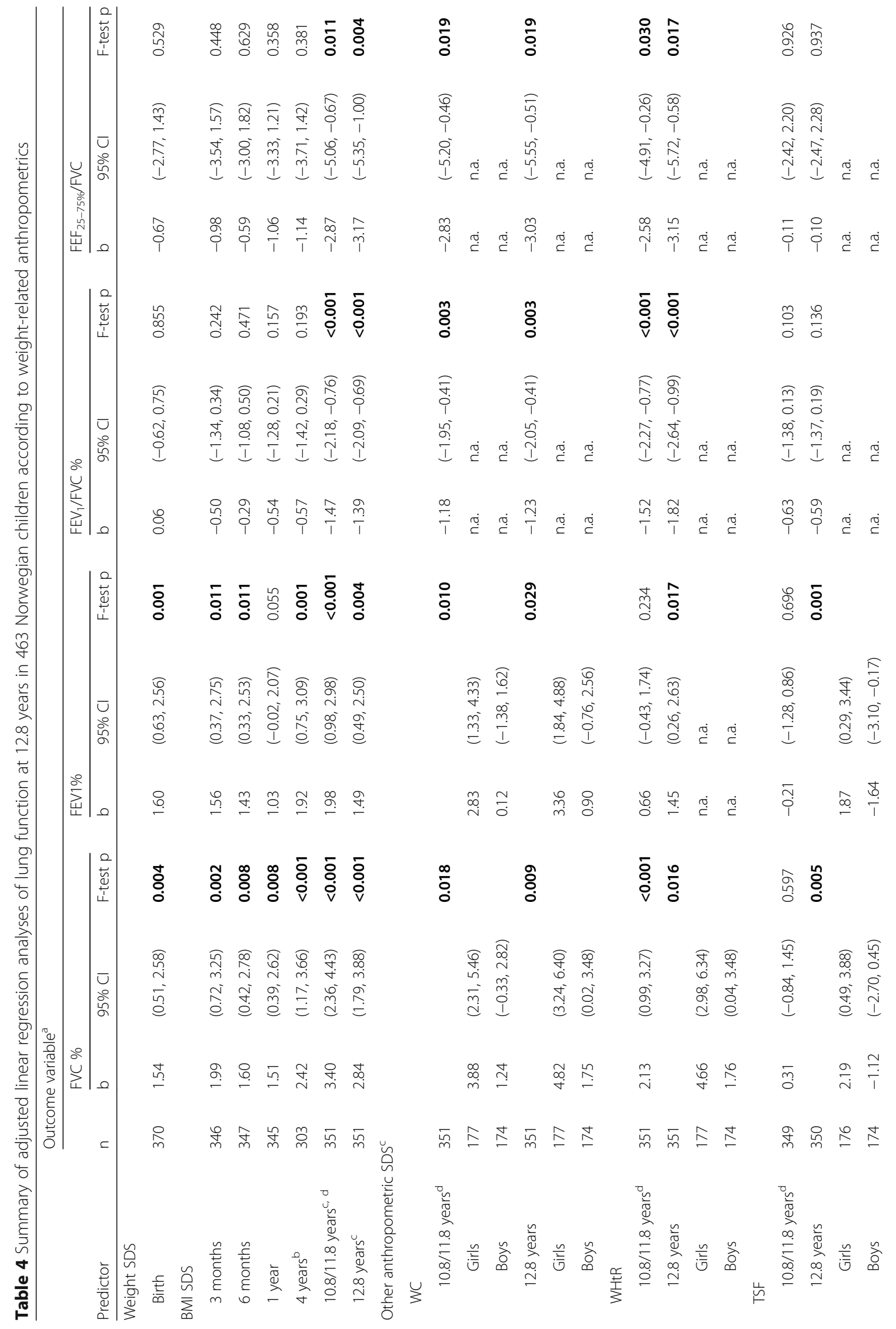




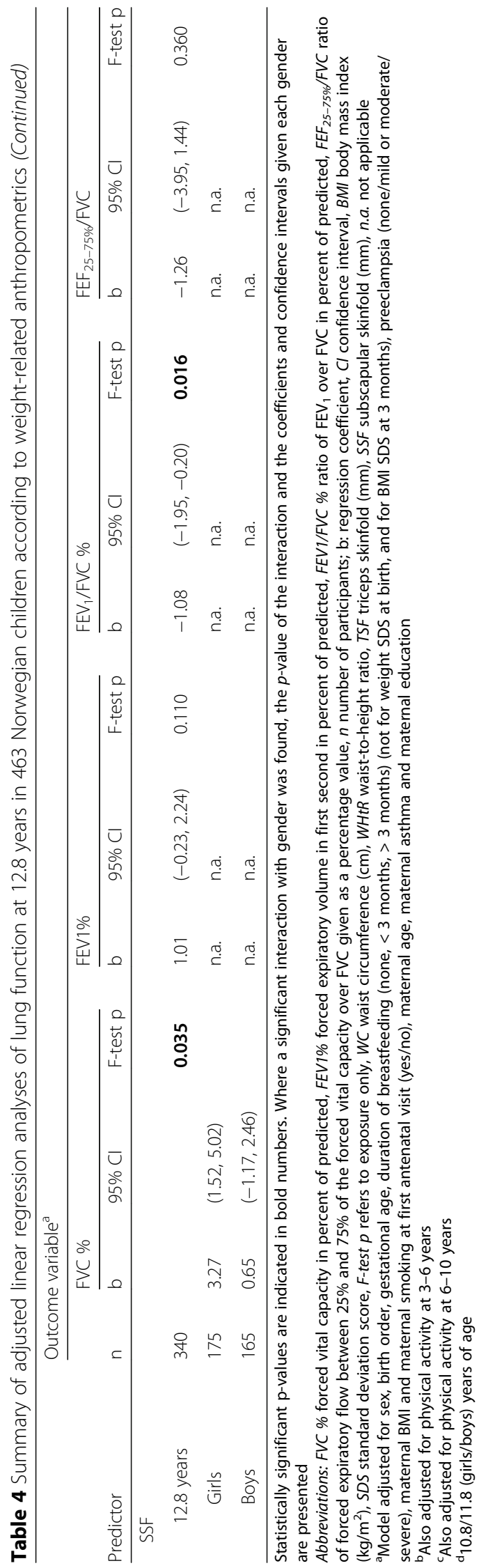




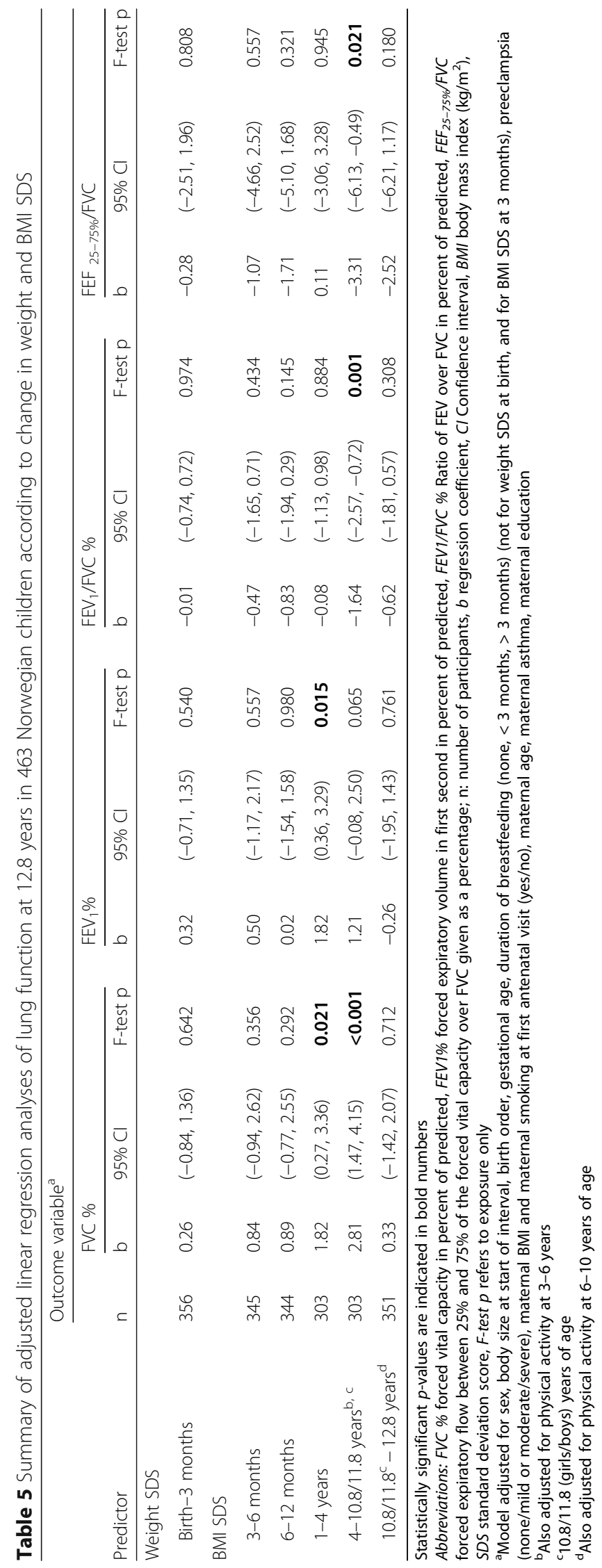




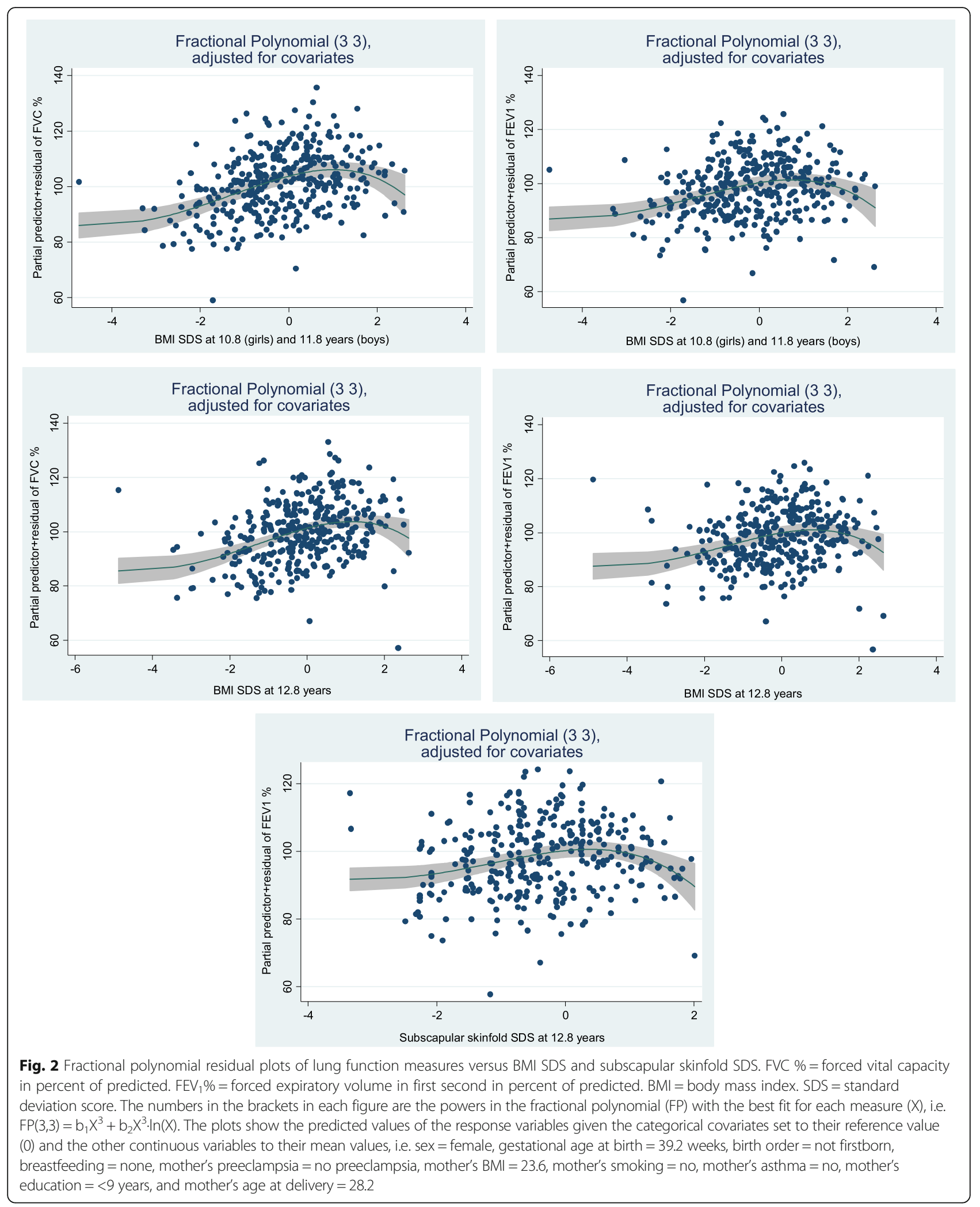


association between childhood BMI and lung volumes is only a result of lean body mass.

The positive associations between anthropometric variables other than $\mathrm{BMI}$ and $\mathrm{FVC} \%$ and $\mathrm{FEV}_{1} \%$ were mainly found in girls, which is consistent with other studies. In a study of 1583 12-year old Canadian children, Khan et al. found that in boys, adiposity was negatively associated with lung function, but not in girls [8]. In a follow up of 11-year old children, Wang et al. found that BMI was positively associated with lung function only in girls, whereas body fat mass was negatively associated with lung function only in boys [43]. These gender specific differences could be due to differences in fat accumulation during and after puberty, with a peripheral fat deposition in girls and an abdominal fat deposition in boys, leading to reduction in lung function in boys [8].

The gender differences in the association between other anthropometric measurements than BMI and FVC $\%$ and $\mathrm{FEV}_{1} \%$ were found only at the second follow-up at 12.8 years of age, except for waist circumference, where the same pattern appeared at the first follow-up at 10.8/11.8 years. This result may support that sex hormones are important determinants not only for anthropometry, but also for lung development [39].

The MFPR analyses in the present study showed inverse U-shaped associations of BMI SDS at the ages of 10.8/11.8 years and 12.8 years with $\mathrm{FVC} \%$ and $\mathrm{FEV}_{1} \%$ at 12.8 years, but no such associations were found for BMI at younger ages. Figure 2 shows a possible inverse relationship in children with a BMI SDS from slightly above 1 corresponding to IOTF class overweight, in accordance with other studies suggesting that BMI beyond a threshold is associated with reduced lung function [10, 13, 44]. When stratifying by gender, the inverse U-shaped associations persisted only for girls at 10.8 years of age, possibly owing to loss of power. In a Mexican study, an inverse U-shaped association between $\mathrm{BMI}$ and $\mathrm{FEV}_{1}$ was found only in children older than 12 years of age [44]. In the PIAMA study with measurements of lung function at 8 and 12 years of age, an inverse U-shaped association of BMI and waist circumference with FVC and FEV1 was found, however the effect size was small and only found in boys [10]. The authors suggested that the transition from the childhood association (high BMI associated with larger lung volume) to the adult association (high BMI associated with smaller lung volumes) takes place later than 12 years [10]. Our results indicate that a transition from a positive to a negative association between BMI and lung function may appear earlier than 12 years for children with the highest BMI. This may be the earliest age indicating the negative association between BMI and lung function seen over a broader range of BMI observed in adults $[5,6]$.

One potential reason for a negative association between obesity and lung volume is a mechanical effect of internal fat deposition, reducing chest wall compliance and impeding diaphragmatic descent [45]. The inverse U-shaped association between subscapular skinfold and $\mathrm{FEV}_{1} \%$ in our study could support this.

A negative association between higher levels of leptin or leptin/adiponectin ratio with lung function could also be mediated by increased systemic inflammation [15], supported by studies showing an association between adiposity and clinical asthma in childhood and adulthood $[15,46]$.

\section{Clinical relevance}

The positive and negative regression coefficients between the anthropometric measures and lung function in the present study are small, i.e. in the range 1-3. Thus, if the predictors increased by one unit (SDS, which is a substantial increase), the predicted lung function values increased or decreased by $1 \%$ to $3 \%$, making the clinical relevance of the results less substantial. However, the inverse U-shaped associations between weight-related anthropometrics and lung function at 10.8-12.8 years of age could suggest that the greater impact of airway obstruction occurs in children with the highest body fat mass.

\section{Strengths and limitations}

The study population was stable and homogeneous regarding socio-economic status and ethnicity. The low participation rate at both follow-ups reduces power, increases the risk of false negative results and may be a source of bias, whereas the loss to follow-up from the first to the second may be a source of selection bias. However, we found no perinatal differences between those who assented to the first follow-up and those who did not assent, nor did baseline characteristics differ between those who participated in the first and second follow-ups.

The study design was longitudinal, but the analyses of the associations between anthropometry and lung function at the second follow-up were cross-sectional. Therefore, reverse causation cannot be excluded. However, as the results were consistent across childhood, reverse causation may be less likely.

This study was originally a follow-up of a nested casecontrol study of preeclampsia, with one-third of the participants exposed to preeclampsia in utero; thus, the cohort is not representative of a general population. However, preeclampsia was adjusted for in the analyses and did not confound the results. Missing responses from the ISAAC questionnaire were interpreted as negative, and we cannot be sure that a missing response was a true negative response for all children. Furthermore, we adjusted the analyses for physical activity, although the questions about physical activity were only validated for adults. 


\section{Conclusions}

In this cohort followed from birth, weight-related anthropometric measures during childhood were positively associated with $\mathrm{FVC} \%$ and $\mathrm{FEV}_{1} \%$ and negatively associated with $\mathrm{FEV}_{1} / \mathrm{FVC} \%$ and $\mathrm{FEF}_{25-75 \%} / \mathrm{FVC}$ in late childhood. Whereas these findings could result from physiological phenomena, increasing weight might also influence the diameter of the airways contributing to airflow limitation. The inverse U-shaped associations of BMI in late childhood with lung volumes and airways size suggest that the highest impact of BMI on lung function occurs in children with the highest BMI.

\section{Additional files}

Additional file 1: Figure S1. Directed Acyclic Graph. Colours of rings: Green = predictor; blue with black dot=outcome; blue = ancestor of outcome; red = potential confounder; black=adjustment set; grey= unavailable/unknown confounders. Red line = biasing path; green line = causal path; black line = closed path. The figure was made by using DAGitty software. (PDF 41 kb)

\section{Abbreviations}

b: Regression coefficient; BMl: Body mass index $\left(\mathrm{kg} / \mathrm{m}^{2}\right)$; Cl: Confidence interval; $\mathrm{FEF}_{25-75 \%}$ : Forced expiratory flow at $25-75 \%$ of forced vital capacity; $\mathrm{FEV}_{1}$ : Forced expiratory volume in the first second; FVC: Forced vital capacity; IBM SPSS: International business machines corporation statistical package for the social sciences; ISAAC: International study of Asthma and Allergy in Childhood; MFPR: Multiple fractional polynomial regression; SDS: Standard deviation score

\section{Acknowledgements}

This is a branch of the Stavanger Study at Stavanger University Hospital. We appreciate the important role of Bjørn Øglænd in the planning of the study and collection of data, and the help of paediatric nurses in the outpatient clinic at the Department of Paediatrics in collecting data. We would also like to thank participating mothers and children.

We thank Biostatistician Ingvild Dalen for statistical advice.

\section{Funding}

The 'Stavanger study' was funded by an internal grant from the National Cancer Institute, National Institute of Health, RO3 (grant number 1 R03CA137754) and is a part of the MD Anderson Global Programme. The present study was funded by a PhD grant for the first author, from the Western Norway Regional Health Authority, grant number 911835.

\section{Availability of data and materials}

All data generated or analysed during this study are included in this published article and its additional files.

\section{Authors' contributions}

MRF and KØ participated in the design of the study. KKB finalised the data collection and registration, performed all the statistical analyses and contributed to writing a draft of the manuscript. IBM contributed to writing a draft of the manuscript. GEE supervised the statistical analyses. PBJ supervised the planning and the drafting of the manuscript and contributed to the analyses of the data. KØ supervised all parts of the study and writing. All authors read and approved of the final manuscript.

\section{Ethics approval and consent to participate}

The study was approved by the Norwegian Data Inspectorate, the Regional Committee for Ethics in medical research Western Norway (Reference Numbers: First: 078-03, Second: 2010/1375), and the Institutional Review Boards of the National Cancer Institute (Reference Number: LAB09-0139) and University of Texas at Austin, United States (Reference Number: 2013-04-0036). Mothers and children signed an informed consent/assent form at the follow-ups.
Consent for publication

Not applicable

\section{Competing interests}

The authors declare that they have no competing interests.

\section{Publisher's Note}

Springer Nature remains neutral with regard to jurisdictional claims in published maps and institutional affiliations.

\section{Author details}

${ }^{1}$ Department of Paediatrics, Stavanger University Hospital, POB 8100, N-4068 Stavanger, Norway. ${ }^{2}$ Department of Clinical Science, University of Bergen, Bergen, Norway. ${ }^{3}$ Centre for Clinical Research, Haukeland University Hospital, Bergen, Norway. ${ }^{4}$ Department of Global Public Health and Primary Care, University of Bergen, Bergen, Norway. ${ }^{5}$ Department of Nutrition Science, Purdue University, West Lafayette, IN, USA. ${ }^{6}$ Department of Paediatrics, Haukeland University Hospital, Bergen, Norway.

Received: 6 June 2017 Accepted: 21 December 2017

Published online: 19 January 2018

\section{References}

1. Lawlor DA, Ebrahim S, Davey Smith G. Association of birth weight with adult lung function: findings from the British Women's Heart and Health Study and a meta-analysis. Thorax. 2005;60(10):851-8.

2. Hancox RJ, Poulton R, Greene JM, McLachlan CR, Pearce MS, Sears MR. Associations between birth weight, early childhood weight gain and adult lung function. Thorax. 2009;64(3):228-32.

3. Kotecha SJ, Watkins WJ, Henderson AJ, Kotecha S. The effect of birth weight on lung spirometry in white, school-aged children and adolescents born at term: a longitudinal population based observational cohort study. J Pediatr. 2015;166(5):1163-7.

4. Barker DJ, Godfrey KM, Fall C, Osmond C, Winter PD, Shaheen SO. Relation of birth weight and childhood respiratory infection to adult lung function and death from chronic obstructive airways disease. BMJ. 1991;303(6804):671-5.

5. Curry BA, Blizzard CL, Schmidt MD, Walters EH, Dwyer T, Venn AJ. Longitudinal associations of adiposity with adult lung function in the Childhood Determinants of Adult Health (CDAH) study. Obesity (Silver Spring). 2011;19(10):2069-75.

6. Ochs-Balcom HM, Grant BJ, Muti P, Sempos CT, Freudenheim JL, Trevisan M, Cassano PA, lacoviello L, Schunemann HJ. Pulmonary function and abdominal adiposity in the general population. Chest. 2006;129(4):853-62.

7. Cibella F, Bruno A, Cuttitta G, Bucchieri S, Melis MR, De Cantis S, La Grutta S, Viegi G. An elevated body mass index increases lung volume but reduces airflow in Italian schoolchildren. PLoS One. 2015;10(5):e0127154.

8. Khan S, Little J, Chen Y. Relationship between adiposity and pulmonary function in school-aged Canadian children. Pediatr Allergy Immuno Pulmonol. 2014;27(3):126-32

9. Chen $Y$, Rennie D, Cormier Y, Dosman JA. Waist circumference associated with pulmonary function in children. Pediatr Pulmonol. 2009;44(3):216-21.

10. Bekkers MB, Wijga AH, Gehring U, Koppelman GH, de Jongste JC, Smit HA Brunekreef B. BMI, waist circumference at 8 and 12 years of age and FVC and FEV at 12 years of age; the PIAMA birth cohort study. BMC Pulm Med. 2015;15(1):39.

11. van der Gugten AC, Koopman M, Evelein AM, Verheij TJ, Uiterwaal CS, van der Ent CK. Rapid early weight gain is associated with wheeze and reduced lung function in childhood. Eur Respir J. 2012;39(2):403-10.

12. Sonnenschein-van der Voort AM, Howe LD, Granell R, Duijts L, Sterne JA, Tilling $K$, Henderson AJ. Influence of childhood growth on asthma and lung function in adolescence. J Allergy Clin Immunol. 2015;135(6):1435-1443 e1437.

13. Suresh S, O'Callaghan M, Sly PD, Mamun AA. Impact of childhood anthropometry trends on adult lung function. Chest. 2015;147(4):1118-26.

14. Li AM, Chan D, Wong E, Yin J, Nelson EA, Fok TF. The effects of obesity on pulmonary function. Arch Dis Child. 2003;88(4):361-3.

15. Jensen ME, Wood LG, Gibson PG. Obesity and childhood asthma mechanisms and manifestations. Curr Opin Allergy Clin Immunol. 2012;12(2):186-92 
16. Mebrahtu TF, Feltbower RG, Greenwood DC, Parslow RC. Childhood body mass index and wheezing disorders: a systematic review and meta-analysis. Pediatr Allergy Immunol. 2015;26(1):62-72.

17. Reilly JJ. Assessment of obesity in children and adolescents: synthesis of recent systematic reviews and clinical guidelines. J Hum Nutr Diet. 2010;23(3):205-11.

18. Maiolo C, Mohamed El, Carbonelli MG. Body composition and respiratory function. Acta Diabetol. 2003;40(Suppl 1):S32-8.

19. Sweeting HN. Measurement and definitions of obesity in childhood and adolescence: a field guide for the uninitiated. Nutr J. 2007;6:32.

20. Brannsether B, Roelants M, Bjerknes R, Juliusson PB. Waist circumference and waist-to-height ratio in Norwegian children 4-18 years of age: reference values and cut-off levels. Acta Paediatr. 2011;100(12):1576-82.

21. Brannsether $B$, Roelants $M$, Bjerknes $R$, Juliusson PB. References and cutoffs for triceps and subscapular skinfolds in Norwegian children 4-16 years of age. Eur J Clin Nutr. 2013;67(9):928-33.

22. Ogland B, Vatten LJ, Romundstad PR, Nilsen ST, Forman MR. Pubertal anthropometry in sons and daughters of women with preeclamptic or normotensive pregnancies. Arch Dis Child. 2009;94(11):855-9.

23. Odegard RA, Vatten LJ, Nilsen ST, Salvesen KA, Austgulen R. Preeclampsia and fetal growth. Obstet Gynecol. 2000;96(6):950-5.

24. Byberg KK, Ogland B, Eide GE, Oymar K. Birth after preeclamptic pregnancies: association with allergic sensitization and allergic rhinoconjunctivitis in late childhood; a historically matched cohort study. BMC Pediatr. 2014;14(1):101.

25. Standardization of Spirometry, 1994 Update. American Thoracic Society. Am J Respir Crit Care Med. 1995;152(3):1107-36.

26. Quanjer PH, Stanojevic S, Cole TJ, Baur X, Hall GL, Culver BH, Enright PL, Hankinson JL, Ip MS, Zheng J, et al. Multi-ethnic reference values for spirometry for the 3-95-yr age range: the global lung function 2012 equations. Eur Respir J. 2012;40(6):1324-43.

27. Byberg KK, Eide GE, Forman MR, Juliusson PB, Oymar K. Body mass index and physical activity in early childhood are associated with atopic sensitization atopic dermatitis and asthma in later childhood. Clin Transl Allergy. 2016;6(1):33.

28. Cole TJ, Lobstein T. Extended international (IOTF) body mass index cut-offs for thinness, overweight and obesity. Pediatr Obes. 2012;7(4):284-94.

29. Worldwide variation in prevalence of symptoms of asthma, allergic rhinoconjunctivitis, and atopic eczema: ISAAC. The International Study of Asthma and Allergies in Childhood (ISAAC) steering committee. Lancet. 1998;351(9111):1225-32.

30. Alsnes IV, Janszky I, Forman MR, Vatten LJ, Okland I. A population-based study of associations between preeclampsia and later cardiovascular risk factors. Am J Obstet Gynecol. 2014;211(6):657 e651-7.

31. Taylor-Piliae RE, Fair JM, Haskell WL, Varady AN, Iribarren C, Hlatky MA Go AS, Fortmann SP. Validation of the Stanford brief activity survey: examining psychological factors and physical activity levels in older adults. J Phys Act Health. 2010;7(1):87-94.

32. Textor J, Hardt J, Knuppel S. DAGitty: a graphical tool for analyzing causal diagrams. Epidemiology. 2011;22(5):745.

33. Niklasson A, Albertsson-Wikland K. Continuous growth reference from 24th week of gestation to 24 months by gender. BMC Pediatr. 2008:8:8.

34. Juliusson PB, Roelants M, Nordal E, Furevik L, Eide GE, Moster D, Hauspie R, Bjerknes R. Growth references for 0-19 year-old Norwegian children for length/height, weight, body mass index and head circumference. Ann Hum Biol. 2013:40(3):220-7.

35. Byberg KK, Oymar K, Eide GE, Forman MR, Juliusson PB. Exposure to preeclampsia in utero affects growth from birth to late childhood dependent on child's sex and severity of exposure: follow-up of a nested case-control study. PLoS One. 2017;12(5):e0176627.

36. Feng K, Chen L, Han SM, Zhu GJ. Ratio of waist circumference to chest circumference is inversely associated with lung function in Chinese children and adolescents. Respirology. 2012;17(7):1114-8.

37. den Dekker HT, Sonnenschein-van der Voort AM, de Jongste JC, Anessi-Maesano I, Arshad SH, Barros H, Beardsmore CS, Bisgaard H, Phar SC, Craig $L$, et al. Early growth characteristics and the risk of reduced lung function and asthma: a meta-analysis of 25,000 children. J Allergy Clin Immunol. 2016;137(4):1026-35.

38. Claudia F, Thiering E, von Berg A, Berdel D, Hoffmann B, Koletzko S, Bauer CP, Koletzko B, Heinrich J, Schulz H. Peak weight velocity in infancy is negatively associated with lung function in adolescence. Pediatr Pulmonol. 2016;51(2):147-56
39. Thompson BR. Dysanapsis-once believed to be a physiological curiosity-is now clinically important. Am J Respir Crit Care Med. 2017:195(3):277-8.

40. ad hoc Statement Committee ATS. Mechanisms and limits of induced postnatal lung growth. Am J Respir Crit Care Med. 2004;170(3):319-43.

41. Forno E, Weiner DJ, Mullen J, Sawicki G, Kurland G, Han YY, Cloutier MM, Canino G, Weiss ST, Litonjua AA, et al. Obesity and airway dysanapsis in children with and without asthma. Am J Respir Crit Care Med. 2017;195(3):314-23.

42. Casas M, den Dekker HT, Kruithof CJ, Reiss IK, Vrijheid M, de Jongste JC, Jaddoe WW, Duijts L. Early childhood growth patterns and school-age respiratory resistance, fractional exhaled nitric oxide and asthma. Pediatr Allergy Immunol. 2016:27(8):854-60.

43. Wang R, Custovic A, Simpson A, Belgrave DC, Lowe LA, Murray CS. Differing associations of BMl and body fat with asthma and lung function in children. Pediatr Pulmonol. 2014;49(11):1049-57.

44. Perez-Padilla R, Rojas R, Torres V, Borja-Aburto V, Olaiz G, The Empece Working G. Obesity among children residing in Mexico City and its impact on lung function: a comparison with Mexican-Americans. Arch Med Res. 2006;37(1):165-71.

45. Lazarus R, Colditz G, Berkey CS, Speizer FE. Effects of body fat on ventilatory function in children and adolescents: cross-sectional findings from a random population sample of school children. Pediatr Pulmonol. 1997:24(3):187-94

46. Boulet LP. Asthma and obesity. Clin Exp Allergy. 2013;43(1):8-21.

\section{Submit your next manuscript to BioMed Central and we will help you at every step:}

- We accept pre-submission inquiries

- Our selector tool helps you to find the most relevant journal

- We provide round the clock customer support

- Convenient online submission

- Thorough peer review

- Inclusion in PubMed and all major indexing services

- Maximum visibility for your research

Submit your manuscript at www.biomedcentral.com/submit

) Biomed Central 